\title{
Pacientes com Doença Oncológica Avançada e o Cuidado de Si a Partir das Relações Interpessoais
}

\author{
Francielly Zilli, ${ }^{1}$ Stefanie Griebeler Oliveira ${ }^{2}$
}

\begin{abstract}
RESUMO
Objetivo: identificar como o cuidado de si de pacientes com doença oncológica avançada é feito a partir das relações interpessoais com familiares, amigos e profissionais da saúde. Método: pesquisa qualitativa, do tipo estudo de caso, tendo como referencial do estudo as teorias pós-críticas, especificamente a vertente pós-estruturalista do campo dos estudos foucaultianos. Participaram do estudo sete pacientes vinculados a um Serviço de Atenção Domiciliar. As informações foram produzidas de março a junho de 2018 com o uso de atividades terapêuticas e observação participante, e foram transcritas e analisadas a partir da aproximação das falas com o código "cuidado de si". Resultados: a partir do cuidado de si estabelecido com os familiares, observamos que os pacientes são instigados a voltar o olhar para si e a se reconhecerem a partir do apoio que recebem. Os amigos oferecem espaços de fala e reconhecimento de si, além de auxiliar no cuidado aos pacientes. A equipe de saúde, por sua vez, direciona o cuidado de si dos pacientes a partir de práticas prescritivas. Conclusões: foi possível identificar, nas falas, o quanto o cuidado de si pode ser incitado pelas relações interpessoais, reforçando o quanto a prática consiste no duplo retorno, estando presente no cotidiano dos pacientes.
\end{abstract}

Palavras-chave: Relações interpessoais. Cuidado paliativo. Câncer.

PATIENTS WITH ADVANCED CANCER DISEASE AND THE CARE

OF THE SELF BASED ON INTERPERSONAL RELATIONSHIPS

\begin{abstract}
Objective: to identify how the care of the self of patients with advanced oncological disease is done from interpersonal relationships with family, friends, and health professionals. Method: qualitative research, case study type, having as reference the post-critical theories, specifically the post-structuralist aspect of the field of foucaultian studies. Seven patients linked to a Home Care Service participated in the study. The production of information was from March to June 2018, and occurred with the use of therapeutic activities and participant observation. The information was transcribed and analyzed from the approximation of the statements with the code "care of the self". Results: from the care of the self established with family members, we observed that patients are encouraged to look back to themselves and recognize themselves from the support they receive. Friends offer spaces for speech and self-recognition, besides helping with patient care. On the other hand, the healthcare team directs the care of the self of patients from prescriptive practices. Conclusions: in the statements, it was possible to identify how much the care of the self can be incited by interpersonal relationships, reinforcing how much the practice consists of double return, being present in the daily life of patients.
\end{abstract}

Keywords: Interpersonal relations. Palliative care. Cancer.

RECEBIDO EM: $17 / 3 / 2020$

MODIFICAÇÕES SOLICITADAS EM: 5/5/2020

ACEITO EM: 14/5/2020

\footnotetext{
Autora correspondente. Bolsista Capes (2018). Universidade Federal de Santa Catarina - UFSC. Rua Eng. Agronômico Andrei Cristian Ferreira, s/n - Trindade, Florianópolis/SC, Brasil. CEP 88040-900. http://lattes.cnpq.br/9116145219376607. https://orcid.org/0000-0001-9697-2709. franciellyzilli.to@gmail.com

2 Universidade Federal de Pelotas - UFPel. Pelotas/RS, Brasil.
} 


\section{INTRODUÇÃO}

A cultura do cuidado de si, apresentada por Foucault, é a forma como o filósofo traduziu o que os gregos chamavam de epiméleia heautoû, a qual contempla diferentes tipos de práticas que permitem direcionar a atenção e o olhar para si, para os modos de ser e para as atitudes consigo, assim como para as formas de ocupação e preocupação (FOUCAULT, 2010).

Compreendemos que o cuidado de si é a ação do sujeito para consigo, a qual implica uma ação para com o outro, reforçando, assim, a ideia de que essa ação não ocupa posição egoísta nas relações. O cuidado de si, portanto, pode ser visto como "duplo retorno": retorno para si, para o outro e para o mundo (GALVÃO, 2014). É o que conduz as atitudes, o modo de estar no mundo e nossas ações - consigo e com o outro (FOUCAULT, 2010).

Acreditamos, ao encontro de outros autores (SILVA; FREITAS, 2015), na compreensão do cuidado de si como potência analítica para a contemporaneidade. A partir dessa noção, é possível entender o sujeito por outra perspectiva, distanciando-se de ideias formativas, tidas como verdades, e as desnaturalizando; ou seja, a partir do cuidado de si, somos incitados a experienciar outras maneiras de ser sujeitos.

Em estudo com idosos, foi identificado que o envolvimento com outras pessoas favorece o reencontro consigo. Espaços de relacionamentos que proporcionam a troca de falas fortalecem o direcionamento do olhar do sujeito para uma compreensão diferente do mundo, a qual possibilita o cuidado de si por meio de um novo encontro consigo, com suas atitudes e com suas novas relações (SCORTEGAGNA et al., 2019).

Ao revisar as pesquisas que investigaram o cuidado de si no âmbito da saúde, observamos que o cuidado de si foi incitado em quem presta o cuidado (cuidadores familiares e profissionais da saúde de diferentes áreas, como atenção domiciliar e saúde mental e da mulher), assim como em pacientes (doentes crônicos de asma e diabetes e deficientes físicos). Exame de consciência, atividade física e ioga, escuta de si, meditação e reflexões sobre a vida, atividades de artesanato e modificação dos hábitos alimentares, estavam entre as técnicas utilizadas para incitação do cuidado de si (ZILLI; PERBONI; OLIVEIRA, 2019).

Diante dos achados que identificam a falta de associação do cuidado de si com pacientes oncológicos, buscamos responder: "Como ocorre o cuidado de si dos pacientes com uma doença oncológica avançada a partir das relações interpessoais estabelecidas?" Para responder essa questão consideramos, além das relações do indivíduo com familiares ou amigos, o que Foucault (2017) abordou sobre a cultura de si na atualidade, uma vez que identificamos uma relação com a estrutura de medicalização instituída e que conduz sujeitos de certas formas no lugar de outras.

Foucault (2017) destaca que as práticas educacionais, pedagógicas, médicas e psicológicas sondam informações para desempenhar um papel formador na atitude dos indivíduos em relação aos outros e a si mesmos, tornando-os dependentes dessas estruturas. Estas têm um caráter medicalizador, que reforça a relação de conhecimento, não uma relação com o sujeito do cuidado (FOUCAULT, 2017). Assim, a relação de conhecimento torna-se cada vez mais ampla e densa, de modo que, quanto mais a medicalização funcionar, menores serão as chances de escapar dela (FOUCAULT, 1977). Essas estruturas deixam claro a ampliação e a inexistência de fronteiras entre a Medicina e as necessidades do sujeito, mostrando que a medicalização passa a ser compreendida como uma intervenção sem demanda, presente de forma cotidiana e transversal no campo social dos sujeitos (ZORZANELLI; CRUZ, 2017).

Conrad (1992) foi o primeiro autor a falar sobre medicalização. Ao tratá-la como um processo, tornou objeto de discussão no campo médico problemas que anteriormente não faziam parte do escopo da Medicina. Assim, os problemas foram definidos e descritos em linguagem médica, aparato médico foi adotado para compreendê-los e intervenções médicas foram utilizadas para tratá-los.

Assim, aqui objetivamos identificar como o cuidado de si de pacientes com doença oncológica avançada é feito a partir das relações interpessoais com familiares, amigos e profissionais da saúde.

\section{MÉTODO}

Trata-se de recorte da dissertação intitulada "Cuidado de si de pacientes com doença oncológica avançada mediado pelas atividades como recurso clínico" (ZILLI, 2018). Foi realizada pesquisa qualitativa, que teve o estudo de caso como abordagem metodológica, com base nas teorias pós-críticas, especificamente na vertente pós-estruturalista do campo dos estudos foucaultianos (PARAísO, 2014).

O estudo de caso é um modo de investigação empírica que pesquisa fatos contemporâneos no contexto da vida em que acontecem, principalmente quando os limites entre fatos e contexto não estão determinados. Essa abordagem metodológica é vista como uma "[...] estratégia de pesquisa abrangente", 
pois parte de variáveis de interesse e conta com várias fontes de evidências, as quais necessitam da convergência das informações coletadas por meio da triangulação dos dados (YIN, 2001, p. 33).

Participaram do estudo sete pacientes com diagnóstico oncológico avançado, todos vinculados ao Serviço de Atenção Domiciliar (SAD) de um hospital universitário do Sul do Brasil. Os participantes foram indicados pelos membros da equipe seguindo os seguintes critérios de inclusão: pacientes acompanhados pelo SAD, com idade superior ou igual a 18 anos, com boas condições de comunicação verbal. Como critério de exclusão, aplicou-se o de não falar o idioma português.

A produção das informações ocorreu de março a junho de 2018, após aprovação do Comitê de Ética em Pesquisa (CEP) por intermédio do parecer no. 2.513.679 e do Certificado de Apresentação para Apreciação Ética (CAAE) no. 82987518.1.00005316. Os participantes da pesquisa foram convidados por meio do Termo de Consentimento Livre e Esclarecido (TCLE), no qual também foram esclarecidos os objetivos e procedimentos a serem realizados durante a pesquisa.

Visando a preservar a identidade dos participantes, orientamos, quando do primeiro encontro, que cada um escolhesse o nome de um pássaro. A ave simboliza a vida, o movimento e a individualidade, e por isso a escolhemos como representatividade de si. Acreditamos que não poderíamos reduzir a presença dos participantes a letras e/ou números. Nesse contexto, o pássaro mais bem representa as características de cada participante: o desejo pela liberdade associada ao voo, a ânsia em bater as asas e a alegria de viver representada pelo colorido das penas e pelos cantos entoados.

Ao total foram 25 horas de entrevistas, resultante de 23 encontros, os quais ocorreram no domicílio dos participantes. Para disparar a produção de informações nos encontros, o terapeuta ocupacional promoveu atividades terapêuticas sustentadas por teorias pós-críticas, as quais defendem que podemos utilizar todos os recursos possíveis para a produção dos dados a fim de obter maior acesso ao objeto de estudo e percorrer diferentes caminhos durante a investigação (PARAÍsO, 2014). Durante todos os encontros, foi usado gravador de voz e realizada a observação participante, que foi registrada em blocos de notas logo após cada encontro.

Para realizar a análise das informações, foi utilizada a versão de demonstração do programa The Ethnograph 6.0. Esse software permitiu que os dados fossem reunidos e analisados a partir do processo de codificação (CASSIANI; ZAGO, 1997). Foi feita a aproximação das falas com ferramentas foucaultianas que direcionaram o código "cuidado de si", o qual possibilitou diferenciar o cuidado de si a partir das relações interpessoais com os familiares e amigos, bem como, por meio da medicalização, com os profissionais da saúde e consigo. No intuito de problematizar a codificação das falas, ao longo da leitura das entrevistas questionamentos foram feitos: "Como se deu a relação com o cuidado ao longo da vida?"; "A forma de cuidado de si muda nos diferentes períodos da experiência de adoecimento?"; Como a experiência do adoecimento altera o viver da pessoa?"

\section{RESULTADOS}

Participaram da pesquisa cinco mulheres - Papagaio (com 43 anos), 01Beija-flor (com 39 anos), 02Beija-flor, ${ }^{3}$ Águia e Sabiá (as três últimas com 34 anos) - e dois homens - Quero-quero (com 72 anos) e Cardeal (com 67 anos). Três categorias de análise foram elaboradas: cuidado de si estabelecido a partir das relações com os familiares, cuidado de si e relações de amizade e, por fim, cuidado de si a partir das recomendações da equipe de saúde. Cada um deles é detalhado a seguir.

\section{Cuidado de si estabelecido a partir das relações familiares}

Ao longo do processo de enfrentamento do adoecer, os participantes voltam o olhar para si e para as relações de cuidado estabelecidas com os familiares, observando e interpretando o cuidado prestado pelos familiares e, então, identificando o cuidado de si a partir dessa relação.

E sempre dizendo, eu agradeço a Deus a família maravilhosa que eu tenho, isso aí é a base do tratamento. [...] Uma glória, porque você ter uma pessoa do teu lado sabendo que você está bem cuidado, isso aí te dá ânimo pra viver. [...] E que nem eu vou ali no banheiro tomar banho, ela [esposa] fica ali (CARDEAL).

Ah, tudo é meu filho. Onde ele entra as coisas mudam muito, eu digo, ele que me levante. Agora, se eu não tivesse ele, será que eu ia ter tanta força pra enfrentar isso tudo? O que eu penso:

Devido à liberdade de escolha dada a cada participante, duas mulheres optaram pelo pássaro beija-flor. A escolha foi respeitada porque cada uma atribuiu à ave características e significados singulares, que representavam o modo como se reconheciam. 
eu tenho que ser forte para poder ajudar ele quando ele precisar de mim. Se eu não tivesse ele, quem ia precisar de mim? Acho que fica mais fácil de me entregar também (PAPAGAIO).

Nas mesmas relações em que os pacientes encontram força para enfrentar as limitações decorrentes do adoecer, identificamos a inversão dos papéis: quem antes cuidava, hoje é cuidado.

Eu me sinto muito só. Eu tinha a minha mãe, que me acompanhava e me ajudava. Em alguns sentidos, ela me ajudava, mas aí ela foi se decaindo, decaindo... Ela morreu com 91 anos. [...] Lembranças que ficaram na memória, e eu me lembro muito da minha mãe, porque eu cuidei dela até o fim da vida dela. Por que eu estou assim? Eu poderia estar bem menos do que eu estou, porque eu poderia ter consultado antes, [...] deixando eu de lado pra cuidar dela (02BEIJA-FLOR).

Ontem mesmo ele [filho] pegou e disse "vai escutar uma musiquinha", e, no momento que eu estava muito chorona, ele dizia "não adianta tu chorar mãe, porque tu chorando tu não vai curar a tua doença, tu vai só piorar" (PAPAGAIO).

Ah, foi um pouco difícil, sempre, mas depois que eu fiquei doente, mesmo, eu dizia pra ela [filha] "eu não tenho culpa, eu não fiquei doente porque eu quis". Tinha que estar dependendo dela... Olha, era tão desagradável. Eu me sentia mal quando tinha que trocar a bolsa... Olha, não gosto nem de pensar. Eu passava muito mal, porque ela vinha, ela tem um gênio muito forte, gritava comigo... Aquilo me deixava muito ruim (ÁGUIA).

\section{Cuidado de si e relações de amizade}

Da mesma forma como os pacientes encontram força e amparo para o cuidado de si nas relações familiares, encontram nas relações de amizade. Identificamos não só o quanto se fortalecem pela existência dessa relação, mas como direcionam o cuidado de si a partir das histórias dos outros.

A minha cunhada mais velha adoeceu primeiro: a mesma doença, a mesma coisa. Aí ela conversava bastante comigo. Aí minha ex-cunhada me passava mensagem, me ligava, vinha seguido aqui também, conversava bastante, me incentivava, me estimulava, porque a irmã dela teve e se curou. Tem uma comadre minha que ela está sempre me mandando mensagem: "comesse hoje? come uma fruta, faz isso, faz aquilo", sempre preocupada, incentivando e estimulando, sabe. Às vezes, do nada, eu estou muito triste e, quando eu vejo, ela manda uma mensagem ou liga pra conversar e é bem na hora que eu preciso... Seguido acontece isso, e é bem bom (SABIÁ).

É muito bom escutar alguém, porque hoje em dia ninguém quer escutar ninguém. As pessoas querem derramar um balde de problema pra pessoa e ele tem que escutar... Se tu vai querer falar alguma coisa, a pessoa não te dá espaço pra te ouvir. Mas quando dá um espaço pra gente começar a falar sobre a gente é muito bom, é bom mesmo, porque aquilo vem lá de dentro de ti, não é da boca pra fora (ÁGUIA).

Assim como identificado nas falas relacionadas ao cuidado de si a partir das relações familiares, identificamos o quanto os amigos proporcionam movimentos de aproximação e resgate das atividades que, antes do adoecer, eram importantes e que hoje contribuem para o cuidado de si dos "pássaros".

Ah, se eu pudesse estar na rua, com meus amigos, tomando chimarrão... Não tem jeito. Às vezes, eles aparecem aí, mas seria bom se a gente tivesse mais liberdade. Não tem essa liberdade, sempre dependendo dos outros. [...] De vez em quando, eu digo "puxa, podia estar na rua tomando chimarrão com meus amigos, aposentado", mas não adianta reclamar, não adianta reclamar de tudo que teria alguma coisa que eu estaria reclamando pra ti aqui agora com certeza (QUERO-QUERO).

As gurias faceiras me esperando [risos]. Eu passei o dia assim, [...] fui uma hora da tarde e fui chegar em casa dez horas da noite, passei o dia lá, bem faceira com as gurias. É bom, eu me sinto bem, porque são pessoas que eu gosto e eu me distraio, porque se eu fico parada dentro de casa, já começo a pensar mil e uma bobagem parada na frente da televisão. [...] É uma pessoa que eu sei que eu vou passar o dia bem, bem cuidada, no meio de pessoas que gostam de mim (PAPAGAIO).

\section{Cuidado de si a partir das recomendações da equipe de saúde}

Os pacientes são subjetivados pelos discursos medicalizantes e, assim, passam a direcionar o cuidado de si de acordo com práticas prescritivas; ou seja, as práticas de si mudam segundo o cuidado prescritivo, oriundo não do conhecimento de si, mas de conhecimento científico. Assim, os sujeitos voltam o olhar para si e se percebem a partir das recomendações da equipe de saúde. 
O pessoal do serviço $X$ todos os dias aqui... $O$ que eu preciso de remédio, eu tenho, então só depende de mim. [...] Eu agora, guria, estou praticamente me cuidando mais - pra ti ver que eu estou de meia, eu estou de roupa, eu estou me cuidando pra não pegar uma gripe agora [...]. O meu banho eu estou tomando perto do horário do meio-dia, que é um horário mais quente... Não tomo mais de manhã, não tomo mais de noite. Estou sempre procurando me agasalhar [...], porque tu sabe que, nessa situação, se tu pega uma gripe, daqui a pouco dá uma coisa no pulmão, lá vai ter que ir eu pro hospital de volta... Então eu a minha parte eu faço em casa. [...] Eu estou me alimentando bem, estou fazendo tudo certinho, estou tomando meus remédios tudo certinho que é pra mim poder o quanto antes eu sair dessa doença [...] (CARDEAL).

Sabe, eu [...] como é que eu vou dizer... Aquele momento ali que eu digo "puxa, mas que dorzinha nojenta, o que eu podia fazer?", no outro dia eu converso com as gurias, mas também não podem me encher de remédio pra não ter dor, porque não é uma dor da doença, eu acho que não. Pra mim, a cama é pior que o câncer nessas alturas. Aí eu só olho para a janela e espero os passarinhos cantar, porque aí eu sei que chegou 6 horas, 7 horas (QUERO-QUERO).

Ah, devido à fraqueza que eu ainda estou muito debilitada, à anemia, que eu tenho muita dores na perna eu tenho muita dor; aí então têm dias que eu até consigo dar uma caminhadinha, [...] mas têm dias que eu não consigo chegar no portão... Então eu queria uma melhora disso, sabe, pra poder sair um pouco mais e ter disposição, porque têm dias que eu estou muito cansada e passo mais deitada (SABIÁ).

[...] não tem o que eu faça que vá passar a minha dor nas minhas pernas moles... Quando elas ficam mole, elas têm que ficar mole. Quando eu tiver que vomitar, eu vou vomitar... Aí eu vou tomando meus remedinhos que ameniza, como se diz, e vou levando. [...] Não adianta a gente se iludir que eu não vou ficar com enjoo: a gente tem que ser realista, eu vou ficar com enjoo e eu vou passar mal. [...] não que eu queira trazer a negatividade para o nosso lado, mas eu sou consciente que, quando eu faço a quimio, eu passo mal (PAPAGAIO).

Essa relação entre sujeito "pássaro" e profissional da saúde se fortalece e influencia os processos de cuidado de si, quando se baseia nas relações de afeto que são estabelecidas entre eles, principalmente pela proximidade favorecida pelo cuidado no domicílio.
Eu e a $X$ [profissional do SAD], a gente ficou muito ligada... A gente fez uma amizade, então qualquer coisinha eu mando um whats pra ela e ela já me ajuda... É bem bacana... Quando eu não estou muito legal, eu mando mensagem pra ela e ela me levanta (SABIÁ).

Olha eu não sei... Eu tinha, tenho uma afinidade com eles [profissionais do $S A D$ ]. E tu vê que às vezes eles vêm aqui e ficam aqui sentados na cozinha - não ficam mais tempo porque eles têm o horário pra cumprir... Eu me considero uma pessoa otimista, sabe, eu não tenho aquelas coisas negativas, mas aí eu converso e "a gente vai na casa de um", eles dizem, "aquela lá é pessimista, é negativa", aquela coisa toda, e eu estou aqui, como até às vezes ela diz "olha só, doente sentada descascando camarão" (ÁGUIA).

\section{DISCUSSÃO}

O cuidado de si é identificado com base nas diferentes relações que se estabeleceram com familiares e amigos ao longo do viver; ou seja, ele constitui-se a partir do cuidado com o outro em relações preestabelecidas. Muitos dos sujeitos que passam a olhar para si a partir do cuidado que agora recebem, deixavam de cuidar de si para cuidar dos outros. Além disso, diante do adoecer, o cuidado de si se fortalece a partir das relações interpessoais com os profissionais da saúde, os quais passam a ocupar o espaço físico dos sujeitos e direcionam muito do olhar que cada um tem em relação a si.

Identificamos que o movimento de voltar o olhar e a atenção para si é instigado a partir do cuidado que cada "pássaro" estabelece com o outro. Saber do amparo, da presença do outro e do apoio à disposição, faz com que cada um volte o olhar para si e se sinta acolhido por saber que conta com uma rede de cuidado familiar presente. São essas relações que permitem resgatar o "viver antigo"; isto é, o contexto do cuidado é ampliado e a rede familiar consegue proporcionar outras experiências diante do adoecer, que não se limitam à rotina doméstica diária.

No curso $A$ hermenêutica do sujeito, ministrado por Foucault no Collège de France, o cuidado de si é abordado a partir das relações interpessoais, de modo a compreendermos o quanto as práticas de si estão associadas a práticas sociais. Segundo o filósofo, portanto, a constituição do cuidado de si está atrelada às relações de si com o outro (FOUCAULT, 2010).

A tarefa de cuidador tende a fortificar o laço familiar, possibilitando que formas de viver possam ser ressignificadas tanto pelo cuidador quanto por 
quem recebe o cuidado (YAVO; CAMPOS, 2016). Outro estudo mostra que fatores relacionados ao papel do cuidador familiar influenciam a qualidade do relacionamento com o ente adoecido (LITZELMAN; KENT; ROWLAND, 2016). Quando existe a possibilidade de realizar o cuidado em domicílio, contexto em que o reconhecimento e a manifestação de sentimentos entre os envolvidos fica ainda mais evidente, verifica-se, de forma mais acentuada, o fortalecimento e a solidificação da relação entre quem cuida e quem é cuidado (WAKIUCHI; SALIMENA; SALES 2015).

O adoecer afasta os "pássaros" da forma como antes haviam estabelecido o cuidado com o outro. Dessa forma, percebemos o quanto direcionam os pensamentos para essas relações, dividindo as preocupações por hoje, em razão do adoecer, não ser mais possível auxiliar no cuidado do outro. Ainda, verbalizam ter dedicado tempo de sua vida cuidando do outro e, portanto, distanciando-se de si, de forma que hoje acabam por não ter mais com quem contar.

Esse movimento de ocupar-se consigo para se ocupar com os outros também é associado a práticas de cuidado de si. É nessa relação com o outro que o sujeito consegue encontrar-se consigo e se fortalecer, como no caso de estudo feito com cônjuges. Neste estudo, foi possível identificar que as experiências socialmente construídas auxiliam no enfrentamento do fim da vida, e isso reflete na condução das práticas medicalizantes, pois as metas de cuidado são compreendidas pelos pacientes e familiares e, assim, alteradas (CHUNG et al., 2018). Embora identifiquemos a inversão dos papéis ocupacionais, são nessas relações que os indivíduos se constituem como sujeitos - hoje enfrentam o adoecer e precisam reconhecer-se diante dessa condição.

Nesse mesmo sentido, os amigos também compartilham histórias, acolhem e direcionam o cuidado a partir da troca de mensagens com palavras de apoio, de demonstração de preocupação e de inúmeras correntes de oração. São eles, também, que auxiliam no resgate de atividades significativas, que direcionam os pensamentos para lembranças boas e que proporcionam que os "pássaros" revivam uma rotina prazerosa.

Identificar, em amigos, aproximações em relação ao adoecimento, fortalece a forma de enfrentar a doença, pois a troca de experiências e afeto produz amparo. Esses movimentos reforçam o quanto devem cuidar de si não só por eles mesmos, mas por todos esses amigos e familiares, os quais direcionam a atenção para cada um dos "pássaros".
A busca por fortalecimento nas relações de amizade identificadas nas falas nos remete à concepção epicurista de amizade, em que esta é apresentada como "[...] inteiramente da ordem do cuidado de si e que é pelo cuidado de si que se deve ter amigos" (FOUCAULT, 2010, p. 176). A amizade, segundo os epicuristas, é associada à utilidade; ou seja, está associada às relações de trocas sociais e de serviços que aproximam os sujeitos. No caso das falas apresentadas, essa utilidade está ligada aos momentos de limitação ou de fraqueza, quando o amigo é o amparo e o fortalecimento no processo de enfrentamento da doença.

Essa confiança relaciona-se com o fato de que o apoio social é visto como peça-chave para a qualidade de vida relacionada com a saúde (KÖLER et al., 2019). As relações de amizade são vistas como essenciais para o comportamento humano; por outro lado, o distanciamento social é apontado como semelhante à dor física (MASCARIN; FERRARI, 2018). Dessa forma, outro estudo corrobora que pacientes adultos jovens consideram os amigos e familiares como a principal fonte de apoio social útil (BREUER et al., 2017).

Ao encontro do que identificamos nas falas apresentadas, Foucault (2010) traz que, além da prestação de serviço com a qual podemos contar na relação de amizade, existe o trabalho, que é o que nos faz amar aqueles que nos despertam a amizade. Isto é, "Trata-se agora de uma estrutura social, da amizade que gira em torno de um indivíduo, mas com vários [outros] a rodeá-lo e que têm seu lugar, lugar que muda conforme a elaboração, o labor realizado por cada qual" (FOUCAULT, 2010, p. 138).

Nas relações com os profissionais da equipe de saúde, por outro lado, o cuidado de si passa a ser sustentado por perspectiva medicalizante, do autoexame de si, fazendo com que ocorram modificações na forma como esses sujeitos olham para si, para seus corpos. Também há modificação na maneira como esses corpos transitam no contexto do lar - sempre com o ideário de estarem cuidando de si sustentados pelo discurso da medicalização dos corpos.

Nesse sentido, os discursos medicalizantes, mediante as relações estabelecidas com os profissionais de saúde, modelam e contornam as práticas de si a partir das prescrições que buscam modificar esses sujeitos e suas rotinas. O produto disso são sujeitos que se constituem mediante um cuidado de si que promove uma relação consigo a partir de cuidado e de controle. Esperam melhoras desde essa relação de cuidado, depositam expectativas nas novas intervenções oferecidas e reconhecem a necessidade de fazer 
muito por si mesmos. Afinal, é isto que encontramos na medicalização, conforme Zorzanelli e Cruz (2017): um discurso que reafirma o modelo de responsabilidade individual.

Nossa compreensão de medicalização vai ao encontro do que prevê Conrad (1992), bem como autores mais atuais (ZORZANELLI; CRUZ, 2017): ela enquadra problemas não médicos como questão de saúde; ou seja, a medicalização da sociedade se dá a partir da reinvenção do objeto do saber médico, ampliando e transformando questões possíveis de intervenção. Essa reinvenção, conforme Gaudenzi e Ortega (2012), ocorre pela normalização de certas condutas morais e prescrições e privações de comportamentos, que são regularizadas pelos saberes dos agentes educativos vinculados às estruturas de caráter medicalizador.

É importante enfatizar que a medicalização - e não somente aquela associada ao papel médico - cada vez mais faz parte dos eventos cotidianos. Isto é, não somente a doença é medicalizada, mas as limitações: a falta de disposição, o reconhecimento de si como um corpo debilitado e a necessidade de se observar e de saber o que o corpo sinaliza são esperados, pois foram normalizados pela medicalização. Dessa forma, observamos que, na contemporaneidade e ao encontro do que preveem Zorzanelli e Cruz (2017), domínios exteriores ao objeto da Medicina, como práticas corporais e morais, também já foram medicalizados, pois a essa característica é atribuído um caráter de fluidez, multiplicidade e complexidade.

Ao mesmo tempo em que a cultura de si atual (FOUCAULT, 2017) - somada à estrutura medicalizante (CONRAD, 1992; FOUCAULT, 1977; ZORZANELLI; CRUZ, 2017) mediante as relações estabelecidas pelo sujeito adoecido; ou seja, dos "pássaros" com os profissionais de saúde - promove um distanciamento do sujeito consigo, do conhecimento que poderia produzir sobre si ou da condução para uma relação consigo, também o faz focar em práticas prescritivas de autoexame, atentando, especialmente, para sinais e sintomas e mudanças de práticas relativas à higiene e à alimentação.

O cuidado de si a partir da relação com a equipe de saúde pode ser associado com o que é apresentado na carta escrita por Marco Aurélio para Frontão, apresentada por Foucault (2010). Nela, Marco Aurélio relata sobre si de forma minuciosa, descrevendo o seu dia; ou seja, fala sobre sua saúde, sobre religião, sobre como está a qualidade de seu sono e sobre como tem desempenhado seus deveres familiares. Assim, faz movimentos de reflexão, de exame de consciência, revendo, no final do dia, tudo o que passou. Des- sa forma, à noite, Marco Aurélio volta o olhar para si, observando-se, e, no dia seguinte, escreve um relato completo para Frontão (FOUCAULT, 2010). O mesmo identificamos nos "pássaros", que se observam e sabem que contam com o apoio da equipe de saúde - é com ela que compartilharão, no dia seguinte, na próxima visita ou mesmo por mensagens de texto, aquilo que identificaram em si a partir desse movimento de reflexão, de olhar para si.

As relações estabelecidas pelos "pássaros" com os profissionais de saúde também se constituem com certa dose de "afeto"; o cuidado recebido e identificado pelos "pássaros", para além de um cuidado clínico, sinaliza segurança. Esse afeto também produz entrelaçamento de relações, as quais proporcionam fortalecimento e sustentação - é o caso das relações familiares e profissionais. Ou seja, para que o cuidado familiar possa acontecer no domicílio, é necessário que seja pontualmente apoiado pelos profissionais da saúde (CORDEIRO; KRUSE, 2019). Dessa forma, identificamos que os "pássaros" se sentem amparados, pois depositam confiança em seus cuidadores, e essa relação de cuidado fortalece ainda mais a relação interpessoal entre eles, a qual é sustentada pela presença da equipe de saúde.

\section{CONCLUSÃO}

Como defendido por Foucault, o cuidado de si não é uma prática egoísta e individual, e isso foi identificado nas falas dos participantes. Dessa forma, observamos o cuidado de si incitado nas relações interpessoais a partir da presença dos familiares, pelo reconhecimento e pela ressignificação do cuidado do outro, o qual instiga o cuidado de si.

Os amigos que estão presentes, mesmo quando fisicamente distantes, oferecem apoio e incitam o cuidado e o movimento de olhar para si, assim como proporcionam espaços para a fala e a escuta, permitindo o compartilhamento de anseios do paciente diante do adoecer.

A equipe de saúde instaura uma nova forma de vigilância de si por meio da cultura de si na atualidade e da medicalização instituída. Ao cuidar, a equipe conduz o cuidado do outro por meio das relações estabelecidas, reforça a observação de si, a atenção sobre si e, consequentemente, o cuidado de si.

Por fim, apontamos a escolha pelo cuidado de si como uma potente ferramenta analítica para a pesquisa, assim como para a prática de cuidado na área de saúde, a qual tornou capaz a ampliação do olhar para o cuidado ofertado, contemplando possíveis re- 
lações que tendem a contribuir para esse processo. Como limitações, apontamos o número de participantes e a compreensão de que esses dados não podem ser generalizados, considerando que os participantes se encontravam no contexto domiciliar, o qual permite interação social com equipe, a família e os amigos de forma distinta daquela estabelecida no contexto hospitalar, por exemplo.

\section{REFERÊNCIAS}

BREUER, N. et al. How do young adults with cancer perceive social support? A qualitative study. Journal of Psychosocial Oncology, 35(3), p. 292-308, 2017.

CASSIANI, S. H. B; ZAGO, M. M. F. A análise de dados qualitativos: a experiência no uso do "The Etnograph". Acta Paul. Enf. São Paulo, 10(1), p. 100-106, 1997.

CHUNG, B. P. M. et al. Byond death and dying: how Chinese spouses navigate the final days with their loved ones suffering from terminal cancer. Support Care Cancer, 26, p. 261267, 2018.

CONRAD, P. Medicalizacion and Social Control. Annual Review of Sociology, Palo Alto, v. 18, n. 12, p. 209-232, Nov. 1992.

CORDEIRO, F. R.; KRUSE, M. H. L. É possível morrer no domicílio? Análise dos cenários brasileiros e francês. Texto $e$ Contexto Enferm., 28, p. e20170602, 2019.

FOUCAULT, M. A hermenêutica do sujeito: curso Collège de France (1981-1982). 3. ed. São Paulo: WMF Martins Fontes, 2010.

FOUCAULT, M. A cultura de si. In: FOUCAULT, M. $O$ que é a crítica? Seguido de A cultura de si. Lisboa: Texto e Grafia, 2017. p. 69-91.

FOUCAULT, M. Historia de la medicalización. Educación Médica y Salud, 11(1), p. 1-25, 1977.

GALVÃO, B. A. A ética em Michel Foucault: do cuidado de si à estética da existência. Instituto, 7(1), p. 157-168, 2014.

GAUDENZI, P.; ORTEGA, F. O estatuto da medicalização e as interpretações de Ivan Illich e Michel Foucault como ferramentas conceituais para o estudo da desmedicalização. Interface - Comunic. Saúde, Educ., 16(40), p. 21-34, 2012.

KÖLER, M. et al. The importance of social relationships for brain tumor patients quality of life: A case for the inclusion of the concepto $f$ disclosure in psycho-oncological care. Journal of Psychosocial Oncology, 26, p. 1-18, 2019.

LITZELMAN, K.; KENT, E. E.; ROWLAND, J. H. Social factors in formal cancer caregivers: The interrelationships among social stressors, relationship quality, and family functioning in the CanCORS dataset. Cancer, 122(2), p. 278-286, 2016.

MASCARIN, M.; FERRARI, A. The concept of friendshio in adolescents with cancer: Reflections and experiences. Tumori Journal, 105(1), p. 5-11, 2018.
PARAíSO, M. A. Metodologia de pesquisas pós-críticas em educação e currículo: trajetórias, pressupostos, procedimentos e estratégias analíticas. In: MEYER, D. E.; PARAíSO, M. A. Metodologias de pesquisas pós-críticas em educação. 2. ed. Belo Horizonte: Mazza Edições, 2014. p. 25.

SCORTEGAGNA, H. M. et al. Cuidado de si em um grupo de convivência de idosas. Rev. Bras. Geriatr. Gerontol, 22(1), p. 2-8, 2019.

SILVA, N. M. A.; FREITAS, A. S. A ética do cuidado de si no campo pedagógico brasileiro: modos de uso, ressonância e desafios. Pro-Posições, 26(1), p. 217-233, 2015.

WAKIUCHI, J.; SALIMENA, A. M. O.; SALES, C. A. Being cared by Family member: the existential feelings of cancer patients. Texto Contexto Enferm., 24(2), p. 381-389, 2015.

YAVO, I. S.; CAMPOS, E. M. P. Cuidador e cuidado: o sujeito e suas relações no contexto da assistência domiciliar. Psicologia: Teoria e Prática, São Paulo, 18(1), p. 20-32, 2016.

YIN, R. K. Estudo de caso: planejamento e métodos. 2. ed. Porto Alegre: Bookman, 2001.

ZILLI, F.; PERBONI, J. S.; OLIVEIRA, S. G. Michel Foucault y el cuidado de sí en el campo de la salud: una revisión integrativa. Revista Cultura de Los Cuidados, (53), p. 28-38, 2019.

ZILLI, F. Cuidado de si de pacientes com doença oncológica avançada mediado pelas atividades como recurso clínico. 2018. 245f. Dissertação (Mestrado) - Programa de Pós-Graduação em Enfermagem da Universidade Federal de Pelotas, 2018.

ZORZANELLI, R. T.; CRUZ, M. G. A. O conceito de medicalização em Michel Foucault na década de 1970. Interface, 22(66), p. 721-731, 2017. 